\title{
Empathy and Regard: Perspectives Held by Graduate Students of Rehabilitation Sciences
}

Alexia E. Metz

University of Toledo, alexia.metz@utoledo.edu

Allison Christoff, OTD, OTR/L

allisonchristoff@gmail.com

Follow this and additional works at: https://nsuworks.nova.edu/ijahsp

Part of the Rehabilitation and Therapy Commons

\section{Recommended Citation}

Metz AE, Christoff, OTD, OTR/L A. Empathy and Regard: Perspectives Held by Graduate Students of Rehabilitation Sciences. The Internet Journal of Allied Health Sciences and Practice. 2020 Jan 01;18(1), Article 10.

This Manuscript is brought to you for free and open access by the College of Health Care Sciences at NSUWorks. It has been accepted for inclusion in Internet Journal of Allied Health Sciences and Practice by an authorized editor of NSUWorks. For more information, please contact nsuworks@nova.edu. 


\title{
Empathy and Regard: Perspectives Held by Graduate Students of Rehabilitation Sciences
}

\begin{abstract}
Purpose: Empathy and regard are understood to be critical to high-quality health care. The purposes of this study were: 1) to increase the representation of the rehabilitation sciences within the literature, 2) to refine the distinctions between empathy and regard, and 3) to examine the relation between empathy and regard within the context of two medical conditions with disparate amounts of associated stigma (cerebrovascular accident [CVA] and human immunodeficiency virus/acquired immunodeficiency syndrome [HIV/AIDS]). Method: Utilizing the Jefferson Scale of Empathy - Health Professions Student version and the Medical Condition Regard Scale, levels of empathy and regard were assessed twice in firstyear graduate students of clinical doctoral programs in occupational therapy and physical therapy and a master's speech-language pathology program, once each in the contexts of CVA and HIV/AIDS. Results: Findings indicate that students of the rehabilitation sciences have empathy levels similar to published levels for students in other health professions; empathy and regard are distinct characteristics, where when assessed in the context of a stigmatized condition, empathy was similar but regard; and empathy and regard positively vary with one another in the context of a stigmatized medical condition Conclusions: This study suggests that there may be unmet potential for training in empathy and a need for increased education on stigmatized medical conditions to enhance regard.
\end{abstract}

\section{Author Bio(s)}

Alexia E. Metz, PhD, OTR/L is associate professor in the occupational therapy doctoral program at the University of Toledo.

Allison Christoff, OTD, OTR/L is an occupational therapist, working for a travel contract company. 


\title{
IITAHSP
}

\section{The Internet Journal of Allied Health Sciences and Practice}

Dedicated to allied health professional practice and education

Vol. 18 No. 1 ISSN 1540-580X

\section{Empathy and Regard: Perspectives Held by Graduate Students of Rehabilitation Sciences}

\author{
Alexia E. Metz ${ }^{1}$ \\ Allison Christoff ${ }^{2}$ \\ 1. University of Toledo \\ 2. Occupational Therapy Clinician \\ United States
}

\begin{abstract}
Purpose: Empathy and regard are understood to be critical to high-quality health care. The purposes of this study were 1) to increase the representation of the rehabilitation sciences within the literature, 2) to refine the distinctions between empathy and regard, and 3) to examine the relation between empathy and regard within the context of two medical conditions with disparate amounts of associated stigma (cerebrovascular accident [CVA] and human immunodeficiency virus/acquired immunodeficiency syndrome [HIVIAIDS]). Method: Utilizing the Jefferson Scale of Empathy - Health Professions Student version and the Medical Condition Regard Scale, levels of empathy and regard were assessed twice in first-year graduate students of clinical doctoral programs in occupational therapy and physical therapy and a master's speech-language pathology program, once each in the contexts of CVA and HIVIAIDS. Results: Findings indicate that students of the rehabilitation sciences have empathy levels similar to published levels for students in other health professions; empathy and regard are distinct characteristics, where when assessed in the context of a stigmatized condition, empathy was similar but regard varied significantly; and empathy and regard positively vary with one another in the context of a stigmatized medical condition. Conclusions: This study suggests that there may be unmet potential for training in empathy and a need for increased education on stigmatized medical conditions to enhance regard.
\end{abstract}

Keywords: empathy, regard, rehabilitation students 


\section{INTRODUCTION}

For professionals in health care, empathy is an important skill for maintaining positive interactions with clients and providing the best quality of care. Empathy is a practitioner's cognitively-based response to a client's emotional and cognitive reactions to an event or situation. ${ }^{1,2}$ The use of empathy by health care practitioners enables the creation of strong client-practitioner relationships, as demonstrated empathy inspires clients to develop courage and hope alongside an understanding and supportive professional. ${ }^{3}$ The implementation of empathy has also been shown to help clients feel validated and respected. ${ }^{4}$

As a personal capacity, empathy varies between individuals, and differences have been noted by profession and region. ${ }^{5-8}$ For students in health care professions, it has been found that empathy is relatively stable quality over the course of their training. $5,7,8$ Targeted training experiences have been successful in enhancing empathy in health care profession students. ${ }^{10,11}$ However, Gallagher and colleagues suggest that empathy may not be amenable to change through brief efforts during didactic education, but rather that empathy training may be effective during experiential learning. ${ }^{12}$

An area of study often explored alongside empathy is practitioner regard for various medical conditions. ${ }^{7,13,14}$ Within health care, regard is defined as the reflection of the "biases, emotions, and expectations a given medical condition descriptor generates." 15 Regard is believed to be centrally influenced by stigmas, which are negative preconceptions and attitudes practitioners hold towards certain medical conditions. ${ }^{15}$ Stigmas are developed from a wide array of sources, including personal experiences and cultural influences..$^{16}$ Three of the most stigmatized conditions within health care are substance abuse disorders, mental illnesses, and human immunodeficiency virus/acquired immunodeficiency syndrome (HIVIAIDS). Stigmas associated with these conditions have been found to alter the mindset of health care practitioners, causing them to become negatively biased and to not consistently provide best client care..$^{17-19}$ Stigmas held by health care providers contribute to the physical, psychological, and social burdens faced by individuals with stigmatized medical conditions. ${ }^{20}$ Research indicates that the stigmatized conditions are typically held in relatively low regard by health care professionals when compared to conditions without widespread stigma. 7,21,22

Researchers have sought to explore both the levels of empathy and levels of regard held by students within a variety of health care fields. However, the methodologies employed within these studies limit the conclusions that can be drawn. Much of the research for empathy and regard has been completed with professionals and students in the fields of nursing, paramedic services, and medcine. $6,13,14,21,23$ In comparison, little research has been done to assess the levels of empathy and regard held by students enrolled in occupational therapy and physical therapy programs. ${ }^{7,8,24} \mathrm{At}$ this time, no research could be found that examines the levels of empathy and regard held by students enrolled in speech-language pathology programs. Additionally, while frequently coupled within the literature, a dearth of research has explored the potential relation between the two.

The purpose of this study was to explore the nature of empathy and regard, as well as the relationship between them, in rehabilitation science students (specifically, students of occupational therapy, physical therapy, and speech-language pathology). It was proposed that empathy, as a personal characteristic that has been demonstrated to be steady over time, does not vary with respect to the stigma associated with client diagnoses; whereas, regard does. Within three rehabilitation science disciplines, we tested the hypotheses 1) that scores on a standard measure of empathy do not differ when administered after reviewing information about health conditions with different levels of stigma at two points in time, and 2) that scores on standard measure of regard would be lower when administered with respect to a condition with high associated stigma than with respect to a condition with low associated stigma. In addition, we explored the relation between empathy and regard by testing for correlation between the scores on standardized tests of empathy and regard in the context of two health conditions.

\section{METHODS}

The methods of the study were approved by the Institutional Review Board of The University of Toledo. We assessed empathy and regard with relation to the medical conditions of cerebrovascular accident (CVA) and human immunodeficiency virus/acquired immunodeficiency syndrome (HIVIAIDS) in first year graduate students in three rehabilitation science professional programs. These were measured using paper-based versions of the Jefferson Scale of Empathy -- Health Professions Student version for empathy and the Medical Condition Regard Scale for regard. 15,25

\section{Participants}

A convenience sample of all first-time, first-year students enrolled in the clinical Doctor of Physical Therapy program (DPT), the clinical Occupational Therapy Doctorate program (OTD), and the master's program for Speech-Language Pathology (MSLP) for the 2016-2017 academic year at a public mid-western university were invited to participate in this study. Cohort sizes in these programs were 28,20 , and 25 students, respectively. Participants had to be 18 years of age or older at the time of the first administration in order to participate. 


\section{Instrumentation}

This study employed two standardized, self-reporting questionnaires, each administered twice to the participants throughout a sixto ten-week period.

\section{Jefferson Scale of Empathy - Health Professions Student Version}

The Jefferson Scale of Empathy - Health Professions Student version (JSE-HPS) is a slightly modified version of the Jefferson Scale of Physician Empathy (JSPE). ${ }^{26,} 27$ The JSE-HPS consists of 20 items, 10 of which are negatively worded to account for the confounding effects of acquiescence responding and are reverse scored upon analysis. The JSE-HPS differs only from the JSPE through the use of an alternate participant identifier (the term physician having been changed to health care provider) within 13 of the 20 total questionnaire items. ${ }^{25}$ When granting permission to use the JSE-HPS in research, the authors require it to be unmodified, including the appearance of the scale's title. Within the JSE-HPS, participants are asked to indicate their level of agreement with each item on a 7-point Likert scale (1= strongly disagree, $7=$ strongly agree). Score results of the JSE-HPS can range between 20 and 140, with a higher score indicating a higher represented level of empathy. The psychometric qualities of the JSE-HPS were assessed by the authors with a convenience sample of 265/285 third- and fourth-year nursing baccalaureate students. The sample was predominately female, aged 20-29 years, white, and earning their first degree. Reported results included internal consistency (Chronbach's coefficient $\alpha$ ) of 0.78 and a test-retest reliability coefficient of 0.69 at a six month interval. ${ }^{22}$ Authors reported differences according to gender (with women scoring higher than men, effect size 0.65 ) but no differences by age, previous degree status, or ethnicity. ${ }^{22}$

\section{Medical Condition Regard Scale}

The Medical Condition Regard Scale (MCRS) consists of 11 items. ${ }^{15}$ Participants are asked to indicate their levels of agreement pertaining to a single medical condition on a 6-point Likert scale ( $A=$ strongly disagree, $F=$ strongly agree). Five of the items on the scale are negatively worded to account for the confounding effects of acquiescence responding and are reverse scored upon analysis. Scores can range from 11 to 66 with a higher score representing a higher indicated level of regard. To be consistent with the presentation of the JSE-HPS, we included the title of the MCRS. Psychometrics were established with convenience samples of first- through fourth-year medical students. Conditions included diagnoses with a variety of stigmatization. The authors reported that the instrument is a valid measure of regard, has a reliability coefficient alpha of .87 , and a test-retest reliability of $.84 .{ }^{15}$ For the MCRS, two item-identical versions of the questionnaires were employed in this study: one requesting responses as pertaining to CVA and another requesting responses pertaining to HIVIAIDS. These conditions were selected due to the potential for treatment from each of the rehabilitation fields included within this study as well as the suggested difference between the stigmas associated with each condition in the literature.

\section{Procedures}

Data collection occurred in a university classroom setting, and participants were recruited by approaching them as a cohort during a program orientation session and/or one or two regularly scheduled classes within their curriculum when no new learning was scheduled to occur. Data were collected in two sessions. Research packets did not prompt participants to supply their names, to allow anonymization of responses. Therefore, researchers prompted students to create (first session) and re-create (second session) a unique identifier that allowed pairing of responses from the two sets of surveys. Students returned their packets, turned face down, by either passing them forward to the researcher or placing them in a stack on the classroom instructor desk. Completion and return of the surveys was inferred to signify informed consent to participate in the study, avoiding collection of a signature. ${ }^{28}$ Participation was voluntary; students could return research packets without responses or not return packets. Researchers made no effort to determine who had or had not completed and/or returned surveys.

\section{First Administration}

Research packets were collated ahead of time and contained the study information sheet which reviewed the purpose of the study, voluntary participation, and the risks and benefits of participation; a demographics sheet; a medical condition information sheet providing a brief definition of either CVA or HIVIAIDS as defined by the World Health Organization (WHO); one of the two versions of the MCRS (corresponding to the condition described in the medical condition information sheet); and one copy of the JSE-HPS. The MCRS preceded the JSE-HPS in half of the research packets, and the JSE-HPS preceded the MCRS in the other half of the packets. In the first administration for each cohort, half of the packets related to CVA and the other half related to HIVIAIDS. The full stack of packets was shuffled prior to distribution. The first administration of the surveys for each cohort required approximately 15 minutes. In this time, the researcher provided a verbal introduction to the study (including emphasis on voluntary participation), distributed research packets, prompted participants to create a unique and anonymous alphanumeric identifier, allowed time for completion of questionnaires, and collected the research packets. 


\section{Second administration}

Prior to the second administration, research packets were collated and labeled for each participant by the unique self-generated participant number, working from a list that indicated which condition the participant responded to in the first administration (CVA or HIV-AIDS) and in which order the surveys were given (JSE-HPS first, MCRS second or vice versa). Each packet contained: a participant identification page, a medical condition information sheet providing brief definitions of either CVA or HIVIAIDS as defined by the WHO, one of the two versions of the MCRS (corresponding to the condition described in the medical condition information sheet), and one copy of the JSE-HPS. The second data collection session occurred at least six weeks and up to ten weeks after the first administration. This administration required up to 20 minutes to complete to ensure that each participant received the survey oriented to the condition he or she did not respond to in the first administration. First, participants were prompted to recreate their unique code on a blank sheet of paper. The researchers then distributed the correct corresponding research packets to the participants. Participants were provided time to complete and return the packets. Researchers reminded students that participation was voluntary.

\section{Data Analysis}

For each of the rehabilitation science programs considered in this study descriptive statistics are reported for demographic characteristics. For each profession, descriptive statistics for calculated scores of the JSE-HPS and MCRS are reported for CVA and HIVIAIDS. The distribution of scores for the JSE-HPS among OTD students demonstrated kurtosis; therefore, non-parametric statistical tests were used throughout. For each discipline, we compared the scores for the JSE-HPS and for the MCRS collected in the context of CVA to those collected in the context of HIVIAIDS using Wilcoxon Signed Rank Tests with a one-tailed criterion of a $=.025$. Effect size is reported, $r$. There were no differences in responses by graduate program (JSE-HPS $X^{2}(2)=1.504,5.376, p=.471$, .68 ; MCRS $X^{2}(2)=.578,3.352, p=.749 .187$ for CVA and HIVIAIDS, respectively); therefore, to explore the relation between empathy and regard, we tested for correlation of JSE-HPS and MCRS scores for all participants collected in the context of each condition using two-tailed Spearman's analysis with significance adjusted to $a=.025$ for multiplicity. Spearman's rho $\left(r_{s}\right)$ was used to indicate effect size. Sample size for analyses run is indicated for each result.

\section{RESULTS}

All first-year students returned surveys indicating consent to participate and supplied demographic information $(n=28,20,25$ for DPT, OTD, MSLP, respectively). All provided at least partial responses to all four surveys administered; however, three participants' responses ( $n=1$ DPT; $n=2$ SLP) could not be used in analysis because of skipped questions $(n=2)$ or illegible responses $(n=1)$. See Table 1 for participant demographics which included all respondents.

Table 1. Participant Characteristics

\begin{tabular}{|r|c|c|c|c|}
\hline & $\begin{array}{c}\text { DPT Partici- } \\
\text { pants (n=28) }\end{array}$ & $\begin{array}{c}\text { OTD } \\
\text { Participants } \\
(\mathrm{n}=20)\end{array}$ & $\begin{array}{c}\text { MSLP } \\
\text { Participants } \\
(\mathrm{n}=25)\end{array}$ \\
\hline Age Range & $\mathrm{n}(\%)$ & $\mathrm{n}(\%)$ & $\mathrm{n}(\%)$ \\
\hline $19-21$ & $4(14 \%)$ & $0(0 \%)$ & $6(24 \%)$ \\
\hline $22-24$ & $28(82 \%)$ & $19(95 \%)$ & $17(68 \%)$ \\
\hline $25-27$ & $1(4 \%)$ & $0(0 \%)$ & $0(0 \%)$ \\
\hline $28-30$ & $0(0 \%)$ & $0(0 \%)$ & $1(4 \%)$ \\
\hline $31-33$ & $0(0 \%)$ & $0(5 \%)$ & $0(0 \%)$ \\
\hline $46-48$ & $0(0 \%)$ & & $1(4 \%)$ \\
\hline
\end{tabular}




\begin{tabular}{|r|c|c|c|c|}
\hline \hline \multicolumn{1}{|c|}{ Gender } & & & & \\
\hline Male & $10(36 \%)$ & $4(20 \%)$ & & $0(9 \%)$ \\
\hline Female & $17(58 \%)$ & $12(60 \%)$ & & $19(76 \%)$ \\
\hline Did not indicate & $1(4 \%)$ & $4(20 \%)$ & & $6(24 \%)$ \\
\hline
\end{tabular}

Scores on surveys assessing empathy and regard were calculated for each of the three disciplines, DPT, OTD, and MSLP (Tables 2 and 3). In all disciplines, scores for empathy were not significantly different when participants responded to the JSE-HPS in the contexts of CVA and HIVIAIDS (Table 2, Figure 1). In all disciplines, scores for regard were significantly lower, with large effect sizes, when participants responded to the MCRS with respect to HIVIAIDS as compared to responses with respect to CVA (Table 3 , Figure 2). When considering CVA, scores reflective of empathy and regard did not significantly correlate with one another $\left(r_{s}=.183\right.$, $p=.129, n=70$, Figure 3). For HIVIAIDS, a positive correlation was significant with a small effect size $\left(r_{s}=.295, p=.013, n=70\right.$, Figure 4).

Table 2. Empathy Scores

\begin{tabular}{|c|c|c|c|c|c|}
\hline & JSE-HPS SC & $\begin{array}{l}\text { Mean } \pm \text { StD } \\
\text { x) }\end{array}$ & & & \\
\hline & CVA & HIVIAIDS & $z$ & $p$ & $r$ \\
\hline DPT $(n=27)$ & $114 \pm 10$ & $112 \pm 12$ & 1.678 & .093 & .32 \\
\hline & $(91-135)$ & $(92-137)$ & & & \\
\hline OTD & $116 \pm 10$ & $114 \pm 9$ & 1.026 & .305 & .23 \\
\hline$(n=20)$ & $(87-132)$ & $(99-130)$ & & & \\
\hline MSLP & $113 \pm 11$ & $111 \pm 10$ & .341 & .733 & .07 \\
\hline$(n=23$ & & & & & \\
\hline
\end{tabular}

Score range: 20-140, comparisons were assessed using Wilcoxon Signed Rank Tests 
Table 3. Regard Scores

\begin{tabular}{|c|c|c|c|c|c|}
\hline & \multicolumn{2}{|c|}{$\begin{array}{c}\text { MCRS scores as Mean } \pm \text { StDev } \\
\text { (min-max) }\end{array}$} & \multirow[b]{2}{*}{$z$} & \multirow[b]{2}{*}{$p$} & \multirow[b]{2}{*}{$r$} \\
\hline & CVA & HIVIAIDS & & & \\
\hline $\begin{array}{l}\text { DPT } \\
(n=27)\end{array}$ & $\begin{array}{l}55 \pm 7(42- \\
66)\end{array}$ & $\begin{array}{l}50 \pm 5 \\
(42-59)\end{array}$ & 3.478 & .001 & .67 \\
\hline $\begin{array}{l}\text { OTD } \\
(n=20)\end{array}$ & $\begin{array}{c}58 \pm 5(49- \\
66)\end{array}$ & $\begin{array}{r}52 \pm 6 \\
(44-63)\end{array}$ & 3.597 & .000 & .80 \\
\hline $\begin{array}{l}\text { MSLP } \\
(n=23)\end{array}$ & $\begin{array}{l}58 \pm 5(44- \\
62)\end{array}$ & $\begin{array}{r}48 \pm 4 \\
(41-56)\end{array}$ & 3.866 & .000 & .80 \\
\hline
\end{tabular}

\section{Empathy}

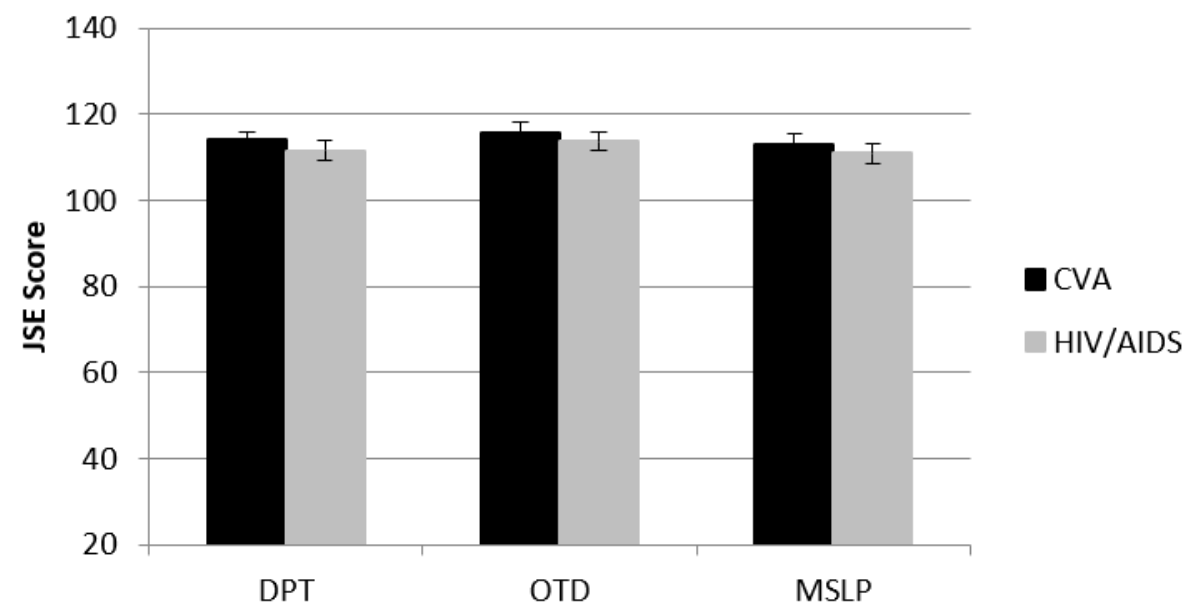

Figure 1. Empathy Scores. Bar charts of the mean JSE-HPS scores for each of the disciplines when the JSE-HPS questionnaire was taken within the context of CVA and HIVIAIDS. Within discipline differences were not significant, tested using Wilcoxon Signed Rank Tests. 


\section{Regard}

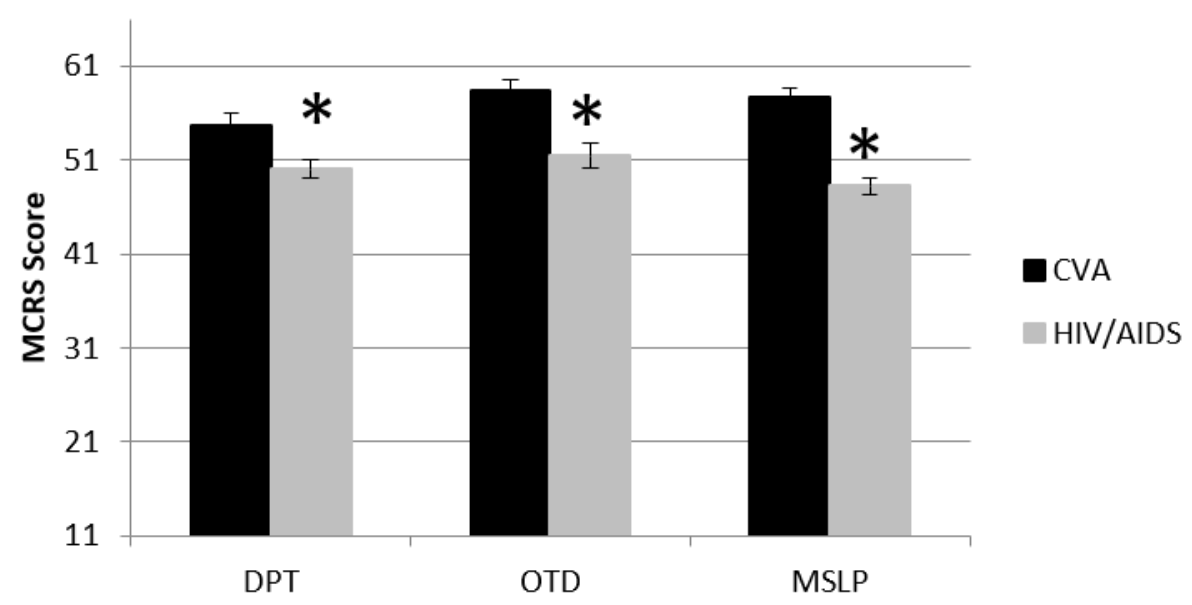

Figure 2. Regard Scores. Bar chart of mean MCRS scores for each of the disciplines within the context of CVA and HIVIAIDS, ( $\left.{ }^{*}\right)$ indicates significance at the $a=.025$ level, tested using Wilcoxon Signed Rank Tests.

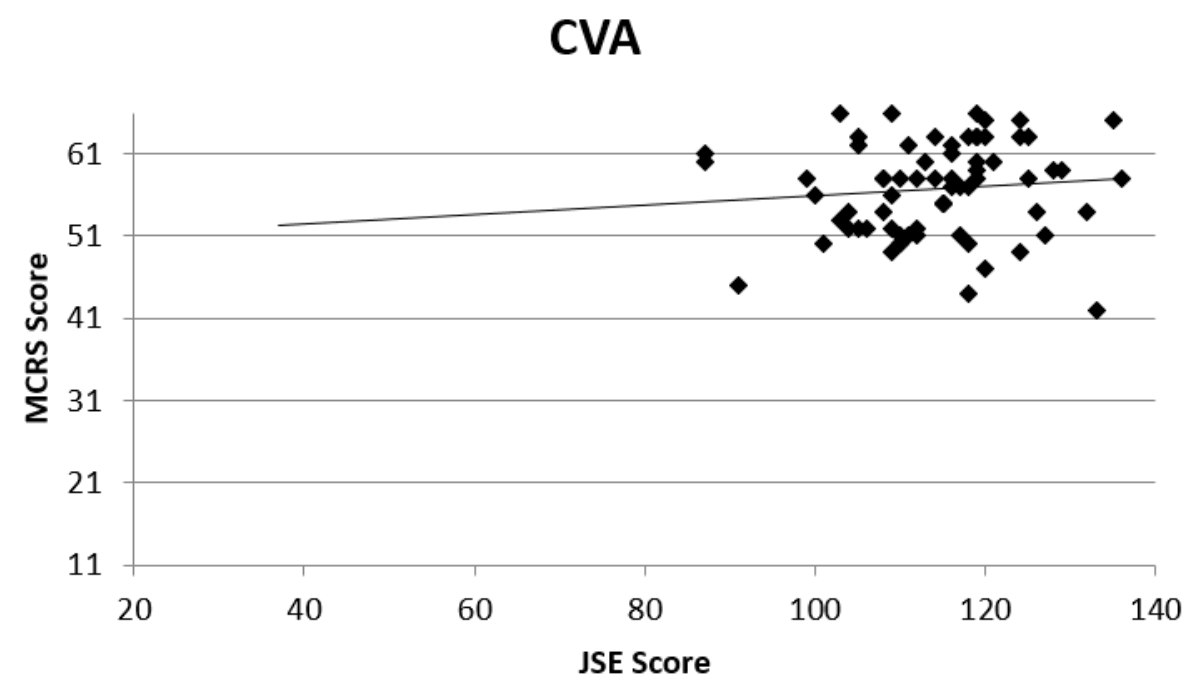

Figure 3. Empathy and Regard Scores in relation to CVA. Scatterplot of all participants' scores on the JSE-HPS and MCRS when completed within the context of CVA. The correlation was not significant $\left(r_{s}=.183, p=.129, \mathrm{n}=70\right)$, tested using a two-tailed Spearman's. 


\section{HIV/AIDS}

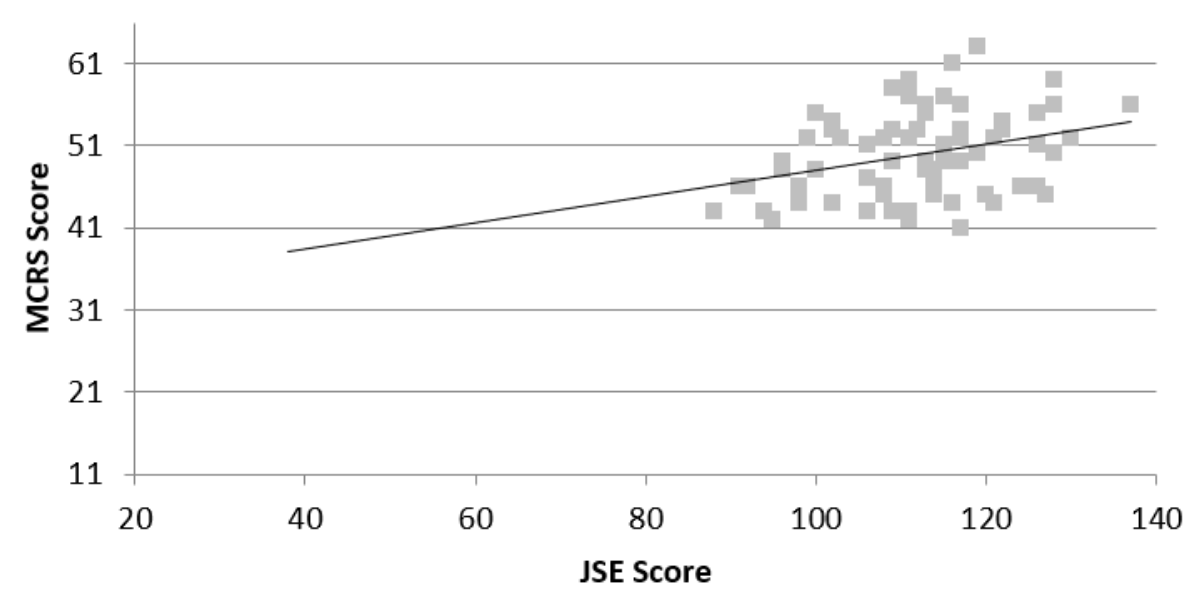

Figure 4. Empathy and Regard Scores in relation to HIVIAIDS. Scatterplot of all participants' scores on the JSE-HPS and MCRS when completed within the context of HIVIAIDS. The correlation was significant $r_{s}=.295, p=.013, n=70$ ), tested using a two-tailed Spearman's.

\section{DISCUSSION}

The findings of this study supported the hypotheses that empathy is a stable personal characteristic that is not influenced by stigma, while regard for clients is influenced by bias held against stigmatized diagnoses. For the first-year students in physical therapy, occupational therapy, and speech-language pathology programs who participated in this study, their respective levels of empathy did not vary when assessed within the context of two conditions with disparate levels of associated stigma.

The levels of empathy found within this study aligned with the limited literature on empathy for occupational therapy and physical therapy students. The mean empathy score for occupational therapy students was identical to the score found in Brown and colleague's study. ${ }^{7}$ Likewise, the mean empathy score found for physical therapy students in this study was within the range of scores found by Gabard and colleagues. ${ }^{8}$ Additionally, the mean scores of empathy found across each of the disciplines within this study (ranging from $111 \pm 10$ to $116 \pm 10$ ) were similar to the mean scores of empathy identified by Williams and colleagues for students in other health care professions (ranging from $106 \pm 13$ to $113 \pm 9$ ). ${ }^{9}$ This finding suggests that the empathy levels students of the rehabilitation sciences possess may be comparable to the levels possessed by students in other health care professions, but the literature is too minimal to validate this statement.

For all disciplines assessed in this study, students' regard for clients with a highly stigmatized medical condition was lower than their regard for clients with a less stigmatized medical condition. The levels of regard for HIVIAIDS found within this study were significantly lower than the levels of regard found for CVA, which is reflective of current literature. ${ }^{17-22}$ These results indicate that the regard levels held by students of the rehabilitation sciences are influenced by stigmas.

Regard and empathy did not correlate with one another when students responded to questionnaires while considering a condition with low associated stigma; however, there was a positive correlation between regard and empathy when students responded while considering a condition with high associated stigma. Though correlation does not provide evidence for causation, this finding may suggest that having higher empathy enhances the capacity to have higher regard for clients with stigmatized conditions. One explanation for this finding could be that when the rehabilitation students considered a lower-stigmatized medical condition (CVA), their reported regard for the condition was relatively high due to the lack of associated biases, and therefore was not affected by their reported level of empathy. Conversely, when health care rehabilitation students considered a highly stigmatized medical condition (HIVIAIDS), those who report higher levels of empathy were able to overlook the condition's associated stigmas to a greater extent than those with lower levels of reported empathy. Given that empathy is a cognitively-based skill, these findings cautiously indicate that training students and clinicians on how to develop and employ empathy can help them look past associated stigmas when treating and working with clients who are diagnosed with highly stigmatized medical conditions. Additionally, through systematic 
review, Wilkinson and colleagues found that empathy has a negative correlation to clinician burnout, wherein low levels of empathy have been assessed to repeatedly correlate with high levels of burnout across diverse healthcare professions and settings. ${ }^{29}$ While research in burnout prevention through empathy training is promising, continued research is needed to explore this phenomenon further. ${ }^{30-32}$

\section{Limitations}

While much of the literature conducted on empathy has included participants from multiple cohorts within an educational program or has been conducted longitudinally, this study only included one cohort of participants from each of the disciplines, all of whom were in their first year of study. Additionally, this study was conducted at one university in the mid-western United States, so generalizing the findings from this study to other universities and geographic areas is inadvisable. The participants in this study were all graduate students, so comparisons to data gathered from undergraduate students in the rehabilitation sciences may be flawed. Moreover, the participants in this study were not a random sample, as all students in the targeted programs were included in data collection and analysis. Participant responses on the surveys may be inaccurate due to response bias. Finally, the participants were informed of the purpose of the study, in broad terms, and the characteristics being assessed were included within the titles of the assessments used and these titles were printed at the top of each assessments' pages. Although data were anonymized, responses may have been influenced by the insight these details provided.

\section{Future Research}

Additional research should be conducted on the explicit relation between empathy and regard and their potential interaction in the case of stigma and medical conditions. As pertaining to the rehabilitation sciences, more research needs to be conducted that explores the levels of regard students of the rehabilitation sciences hold towards other medical conditions with varying degrees of associated stigma. Additionally, research exploring empathy and regard needs to be conducted with rehabilitation students during their experiential training and with practicing physical therapists, occupational therapists, and speech-language pathologists, in order to gain a greater understanding of empathy and regard in professional development and practice. Research should test the effects of education about stigmatized conditions and empathy training on regard across the time course of professional development.

\section{CONCLUSION}

Empathy in health care practitioners is critical to best-practices care and client outcomes. Here, we provide evidence that empathy may not be susceptible to biases associated with stigmatized health conditions, where regard may be. Further, we provide preliminary evidence that having greater empathy may mitigate the effects of stigma. Together, these findings suggest that teaching and training aimed at enhancing empathy may indirectly affect regard, though this must be tested. Published studies have suggested that empathy training is effective in increasing empathy, with some suggesting that interventions would be most effective if in experiential situations. ${ }^{10-12}$ During didactic portions of health care professional education for students and continuing education programs for clinicians, perhaps instruction should a) introduce importance of empathy and its application to clinical practice, b) provide introductory experiential training in empathy (such as self-reflection, role playing, and work with simulated/standardized clients), c) introduce the topics of bias, stigma, and regard and their effects on client care, d) review commonly stigmatized health conditions, including their etiologies and the needs of clients who have them, and e) provide students opportunities to self-assess and challenge their biases. ${ }^{19-21}$ Educational programs may incorporate experiential learning opportunities into their curricula that intentionally and specifically include work with clients who face complex challenges and present with stigmatized conditions. During experiential training, student practitioners should continue to receive training in empathy and regard, drawing on their clinical experiences with clients. Examples can include self-reflection through journaling, client interview, literature reviews about stigmatized condition, and guided workshops. ${ }^{12}$

\section{REFERENCES}

1. Chismar D. Empathy and sympathy: The important difference. The Journal of Value Inquiry. 1988; 22(4), 257-266. [doi.10.1007/BF00136928]

2. Hojat M. Empathy in patient care: Antecedents, development, measurement, and outcomes. 2007. New York, NY: Springer Science and Business Media. [ISBN 978-0-387-33608-4]

3. Peloquin SM. The fullness of empathy: Reflections and illustrations. American Journal of Occupational Therapy. 1995; 49(1), 24-31. [PMID: 7892898]

4. Coulehan JL, Platt FW, Egener B, Frankel R, Lin CT, Lown B, Salazar WH. "Let me see if I have this right...": Words that help build empathy. Annals of Internal Medicine. 2001; 135(3), 221-227. [PMID: 11487497] 
5. Hojat M, Gonnella JS, Nasca TJ, Mangione S, Vergare M, Magee M. Physician empathy: Definition, components, measurement, and relationship to gender and specialty. American Journal of Psychiatry. 2002; 159, 1563-1569. [PMID:12202278]

6. Williams B, Brown T, McKenna L, Boyle MJ, Palermo C, Nestel D, Brightwell R, McCall L, Russo V. Empathy levels among health professional students: A cross-sectional study at two universities in Australia. Advances in Medical Education and Practice. 2014; 5, 107-113. [PMID: 24833947]

7. Brown T, Williams B, Boyle M, Molloy A, McKenna L, Molloy L, Lewis B. Levels of empathy in undergraduate occupational therapy students. Occupational Therapy International. 2010; 17(3), 135-141. [ PMID:20623554]

8. Gabard D, Low, D, Deusinger S, Stelzner D, Crandall S. Analysis of empathy in doctor of physical therapy students: A multi-site study. Journal of Allied Health. 2013; 42(1), 10-16. [PMID: 23471280]

9. Williams B, Brown T, Boyle M, McKenna L, Palermo C, \& Etherington J. Levels of empathy in undergraduate emergency health, nursing, and midwifery students: A longitudinal study. Advances in Medical Education and Practice. 2014; 5 , 299-306. [PMID: 25246815]

10. Bas-Sarmiento, P, Fernández-Gutiérrez M, Baenan-Baňos m, Romero-Sánchez JM. Efficacy of empathy training in nursing student: A quasi-experimental study. Nursing Education Today, 2017; 59: 59-65. [PMID: 28945994]

11. Wündrich M, Schwartz C, Feige B, Lemper D, Nissen C, Voderholzer U. Empathy training in medical students: A randomized controlled trial. Medical Teaching, 2017; 39(10), 1096-1098. [PMID: 289749198]

12. Gallagher $\mathrm{P}$, Moriarty H, Huthwait M, Lim B. Challenging some assumptions about empathy. The Clinical Teacher, 2017; 14(6), 437-440. [PMID: 28150378]

13. McKenna L, Boyle M, Brown T, Williams B, Molloy A, Lewis B, Molloy L. Levels of empathy in undergraduate nursing students. International Journal of Nursing Practice, 2012; 18(3), 246-251. [PMID: 22621294]

14. Williams B, Boyle M, Fielder C. Empathetic attitudes of undergraduate paramedic and nursing students towards four medical conditions: A three-year longitudinal study. Nurse Education Today, 2015; 35(2), e14-e18. [PMID: 25573748]

15. Christison GW, Haviland MG, Riggs ML. The Medical Condition Regard Scale: Measuring reactions to diagnoses. Academic Medicine, 2002; 77(3), 257-262. [PMID: 11891166]

16. Yang L, Kleinman A, Link B, Phelan J, Lee S, Good B. Culture and stigma: Adding moral experience to stigma theory. Social Science \& Medicine, 2007; 64(7), 1524-1535. [PMID: 17188411]

17. Van Boekel L., Brouwers EP, Van Weeghel J, Garretsen HF. Stigma among health professionals towards patients with substance use disorders and its consequences for healthcare delivery: Systematic review. Drug and Alcohol Dependence, 2013; 131(1), 23-35. [PMID: 23490450]

18. Corrigan PW, Druss BG, Perlick DA. The impact of mental illness stigma on seeking and participating in mental health care. Psychological Science in the Public Interest, 2014; 15(2), 37-70. [PMID: 26171956]

19. Mahajan AP, Sayles JN, Patel VA, Remien RH, Ortiz D, Szekeres G, Coates TJ. Stigma in the HIVIAIDS epidemic: A review of the literature and recommendations for the way forward. AIDS, 2008; 22(2), 67-79. [PMID: 18641472]

20. Weiss MG, Ramakrishna J, Somma D. Health-related stigma: Rethinking concepts and interventions. Psychology, Health \& Medicine, 2006; 11(3), 277-287. [PMID: 17130065]

21. Dearing KS, Steadman S. Challenging stereotyping and bias: A voice simulation study. Journal of Nursing Education, 2008; 47(2), 59-65.[ PMID: 18320956]

22. Nutt RA, Gilchrist G, Sambola FM, Baldacchino AM. Staff regard towards working with patients who have co-morbid depression and substance misuse disorders. Heroin Addiction and Related Clinical Problems. 2016; 19(2), 5-16

23. Quince TA, Kinnersley P, Hales J, da Silva A, Moriarty H, Thiemann P, Hyde S, Brimicombe J, Wood D, Barclay M, Benson J. Empathy among undergraduate medical students: A multi-centre cross-sectional comparison of students beginning and approaching the end of their course. BMC Medical Education, 2016; 16(1), 92-102. [PMID: 26979078]

24. Boyle M, Williams B, Brown T, Molloy A, McKenna L, Molloy L, Lewis B. Levels of empathy in undergraduate health science students. The Internet Journal of Medical Education, 2010; 1(1).

25. Fields SK, Mahan $P$, Tillman $P$, Harris J, Maxwell K, Hojat M. Measuring empathy in health care profession students using the Jefferson Scale of Physician Empathy: Health provider-student version. Journal of Interprofessional Care, 2011; 25(4), 287-293.[ PMID: 21554061]

26. Hojat M, Mangione S, Nasca TJ, Cohen MJ, Gonnella JS, Erdmann JB, Veloski J, Magee M. The Jefferson Scale of Physician Empathy: Development and preliminary psychometric data. Educational and Psychological Measurement, 2001; 61(2), 349-365. [doi.10.1177/00131640121971158]

27. Hojat, M. Empathy in health professions education and patient care. New York, New York: Springer International. 2016; [ISBN 978-3-319-27625-0]

28. Singer, E. Risk, benefit, and informed consent in survey research. Survey Research, 2004; 35(2-3), 1-6.

29. Wilkinson, H., Whittington, R., Perry, L., \& Eames, C. Examining the relationship between burnout and empathy in healthcare professionals: A systematic review. Burnout Research, 2017; 6, 18-29. 
30. Cho, E., \& Jeon, S. The role of empathy and psychological need satisfaction in pharmacy students' burnout and wellbeing. BMC medical education, 2019; 19(1), 43.

31. Thirioux, B., Birault, F., \& Jaafari, N. Empathy is a protective factor of burnout in physicians: new neuro-phenomenological hypotheses regarding empathy and sympathy in care relationship. Frontiers in psychology, 2016; 7, 763.

32. Yu, H., Jiang, A., \& Shen, J. Prevalence and predictors of compassion fatigue, burnout and compassion satisfaction among oncology nurses: A cross-sectional survey. International Journal of Nursing Studies, 2016; 57, 28-38. 